\title{
Avoidable cancers in the Nordic countries-the potential impact of increased physical activity on postmenopausal breast, colon and endometrial cancer
}

\section{Andersson, Therese M-L.}

2019-03

Andersson, T M-L, Engholm , G , Lund, A-S Q, Lourenco , S , Matthiessen , J , Pukkala , E , Stenbeck , M , Tryggvadottir , L , Weiderpass , E \& Storm , H 2019 , ' Avoidable cancers in the Nordic countries-the potential impact of increased physical activity on postmenopausal breast, colon and endometrial cancer ' , European Journal of Cancer , vol. 110 , pp. 42-48 . https://doi.org/10.1016/j.

http://hdl.handle.net/10138/313333

https://doi.org/10.1016/j.ejca.2019.01.008

unspecified

publishedVersion

Downloaded from Helda, University of Helsinki institutional repository.

This is an electronic reprint of the original article.

This reprint may differ from the original in pagination and typographic detail.

Please cite the original version. 


\title{
Avoidable cancers in the Nordic countries - the potential impact of increased physical activity on postmenopausal breast, colon and endometrial cancer
}

\author{
Therese M-L. Andersson ${ }^{\mathrm{a}, *}$, Gerda Engholm ${ }^{\mathrm{b}}$, Anne-Sofie Q. Lund ${ }^{\mathrm{c}}$, \\ Sofia Lourenço ${ }^{\mathrm{c}}$, Jeppe Matthiessen ${ }^{\mathrm{d}}$, Eero Pukkala ${ }^{\mathrm{e}, \mathrm{f}}$, \\ Magnus Stenbeck ${ }^{\mathrm{g}}$, Laufey Tryggvadottir ${ }^{\mathrm{h}, \mathrm{i}}$, Elisabete Weiderpass ${ }^{\mathrm{a}, \mathrm{j}, \mathrm{k}, \mathrm{l}}$, \\ Hans Storm ${ }^{m}$
}

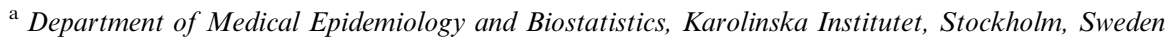

${ }^{\mathrm{b}}$ Department of Documentation \& Quality, Danish Cancer Society, Copenhagen, Denmark

${ }^{c}$ Department of Cancer Prevention and Information, Danish Cancer Society, Copenhagen, Denmark

${ }^{\mathrm{d}}$ Division of Risk Assessment and Nutrition, National Food Institute, Technical University of Denmark, Kgs. Lyngby, Denmark

${ }^{\mathrm{e}}$ Finnish Cancer Registry - Institute for Statistical and Epidemiological Cancer Research, Helsinki, Finland

${ }^{\mathrm{f}}$ Faculty of Social Sciences, University of Tampere, Tampere, Finland

${ }^{\mathrm{g}}$ Department of Clinical Neuroscience, Division of Insurance Medicine, Karolinska Institutet, Stockholm, Sweden

${ }^{\mathrm{h}}$ Icelandic Cancer Registry, Icelandic Cancer Society, Reykjavik, Iceland

${ }^{\mathrm{i}}$ Faculty of Medicine, University of Iceland, Reykjavik, Iceland

${ }^{\mathrm{j}}$ Department of Research, Cancer Registry of Norway - Institute of Population-Based Cancer Research, Oslo, Norway

${ }^{\mathrm{k}}$ Genetic Epidemiology Group, Folkhälsan Research Center, Faculty of Medicine, Helsinki University, Helsinki, Finland

${ }^{1}$ Department of Community Medicine, University of Tromsø, The Arctic University of Norway, Tromsø, Norway

${ }^{\mathrm{m}}$ Danish Cancer Society, Copenhagen, Denmark
}

Received 12 November 2018; received in revised form 28 December 2018; accepted 5 January 2019

Available online 7 February 2019

\section{KEYWORDS \\ Moderate and vigorous physical activity; Cancer; Prevention; Population attributable fraction;}

\begin{abstract}
Background: Physical activity has been shown to reduce the risk of colon, endometrial and postmenopausal breast cancer. The aim of this study was to quantify the proportion of the cancer burden in the Nordic countries linked to insufficient levels of leisure time physical activity and estimate the potential for cancer prevention for these three sites by increasing physical activity levels.

Methods: Using the Prevent macrosimulation model, the number of cancer cases in the Nordic countries over a 30-year period (2016-2045) was modelled, under different scenarios of increasing physical activity levels in the population, and compared with the projected number
\end{abstract}

* Corresponding author: Department of Medical Epidemiology and Biostatistics, Karolinska Institutet, Box 281, 17177 Stockholm, Sweden. E-mail address: therese.m-l.andersson@ki.se (T.M.-L. Andersson). 
Potential impact

fraction;

Nordic countries;

Prevent

macrosimulation

model;

Breast cancer;

Colon cancer;

Endometrial cancer of cases if constant physical activity prevailed. Physical activity (moderate and vigorous) was categorised according to metabolic equivalents (MET) hours in groups with sufficient physical activity (15+ MET-hours/week), low deficit ( 9 to $<15$ MET-hours/week), medium deficit ( 3 to $<9$ MET-hours/week) and high deficit (<3 MET-hours/week).

Results: If no one had insufficient levels of physical activity, about 11,000 colon, endometrial and postmenopausal breast cancer cases could be avoided in the Nordic countries in a 30-year period, which is $1 \%$ of the expected cases for the three cancer types. With a $50 \%$ reduction in all deficit groups by 2025 or a $100 \%$ reduction in the group of high deficit, approximately $0.5 \%$ of the expected cases for the three cancer types could be avoided. The number and percentage of avoidable cases was highest for colon cancer.

Conclusion: 11,000 cancer cases could be avoided in the Nordic countries in a 30-year period, if deficit in physical activity was eliminated.

(c) 2019 Elsevier Ltd. All rights reserved.

\section{Introduction}

Strong evidence shows that physical activity of both moderate and vigorous intensity has a direct protective effect against cancer of the colon, breast (postmenopause) and endometrium [1-4] and potentially decreases the risk of more cancer sites $[5,6]$. Despite the fact that physical activity decreases the risk of several diseases, a fourth of the adult population worldwide does not meet the minimum guidelines [7]. From 2001 to 2016, the prevalence of physical inactivity increased almost six percentage points in high-income Western countries (including Denmark, Sweden, Finland and Norway) resulting in $36,8 \%$ of the population with an insufficient physical activity level in 2016 [7]. It is therefore relevant to estimate the impact of an increase in the level of physical activity on cancer incidence. This is, to our knowledge, the first study aimed at estimating the total number and proportion of preventable cases for breast, colon and endometrial cancers in the Nordic countries according to different scenarios of increased levels of physical activity.

\section{Material and methods}

The Prevent macrosimulation model $[8,9]$ was used to model projections of the number of cancer cases in the Nordic countries in the 30-year period, 2016-2045. A more detailed description of the Prevent model can be found elsewhere [9,10], and we used a similar approach as in other Nordic studies to estimate avoidable cancers according to changes in prevalence of smoking, alcohol consumption and overweight/obesity [11-13]. We applied the Prevent model separately to each country and to the three cancer sites investigated-postmenopausal breast (defined as breast cancer diagnosed at age 50 years and above), colon and endometrial cancer-and for three investigated hypothetical scenarios (see below). The Prevent model requires data on disease incidence, projected population size, risk factor prevalence, relative risk (RR) estimates and changes in risk factor prevalence under hypothetical scenarios of interest.

Incidence rates, by cancer site, country, gender and age groups, were based on the incidence during the years 2009-2013 and obtained from NORDCAN [14-16]. Table 1 lists the International Classification of Diseases (ICD) codes used to define the cancer sites and the average annual number of cases in the Nordic countries. The estimated population size in the years 2016-2045, by gender and 5-year age groups, was obtained from population projections by the statistical bureaus in the respective countries [17-21].

Data from the Nordic Monitoring System on diet, physical activity and overweight in the Nordic Countries (the NORMO study), which includes self-reported survey data for physical activity, were used to estimate current activity levels in the Nordic countries. The

Table 1

Cancer sites, relative risk estimates and the average annual incident cases (2009-2013) in the Nordic countries.

\begin{tabular}{|c|c|c|c|c|c|}
\hline \multirow[t]{2}{*}{ Cancer site } & \multirow[t]{2}{*}{ ICD-10 code } & \multirow{2}{*}{$\begin{array}{l}\text { Avg. \# cases per year } \\
\text { in the Nordic countries }\end{array}$} & \multicolumn{3}{|l|}{ Relative risk } \\
\hline & & & $\begin{array}{l}\text { Low deficit }(9-<15 \\
\text { MET-hours per week) }\end{array}$ & $\begin{array}{l}\text { Moderate deficit ( } 3 \text { to }<9 \\
\text { MET-hours per week) }\end{array}$ & $\begin{array}{l}\text { High deficit }(<3 \\
\text { MET-hours per week) }\end{array}$ \\
\hline Breast, age $50+$ & $\mathrm{C} 50$ & 16,139 & 1.006 & 1.018 & 1.028 \\
\hline Colon & $\mathrm{C} 18$ & 11,280 & 1.012 & 1.037 & 1.056 \\
\hline Endometrium & C54 & 3736 & 1.006 & 1.018 & 1.028 \\
\hline
\end{tabular}

MET, metabolic equivalents. 
information on leisure time (including transportation) physical activity was converted from hours to metabolic equivalents hours (MET-h), based on the assumption that $1 \mathrm{~h}$ of moderate intensity physical activity corresponds to 3 MET-h and that $1 \mathrm{~h}$ of vigorous intensity physical activity corresponds to 6 MET-h [22]. We then categorised the MET-h per week in $<3,3$ to $<9,9$ to $<15,15+$ and refer to these groups as high deficit, medium deficit and low deficit in physical activity and reference group (sufficient level of physical activity). The data used in Prevent are the proportion of individuals, by country, gender and age group, in each of the categories, in 2011 and 2014. More information about the data can be found in Appendix A, together with the prevalence in each category in year 2014 by country, gender and age group.

We assumed that 15 or more MET-h per week are sufficient to avoid increased risk of cancer. This is higher than the general World Health Organisation (WHO) recommendation, but this cut-off has been used previously for estimating the population attributable fraction (PAF) of physical activity on cancer [23], and for cancer prevention, it is likely that the greater the amount of physical activity the greater the benefit [24]. The RRs for low deficit ( 9 to $<15$ MET-h per week), medium deficit $(3$ to $<9)$ and high deficit $(<3)$ were estimated based on results from the World Cancer Research Fund Continuous Update Project (WCRF CUP) [1] and are presented in Table 1. The RRs from the WCRF CUP give the decrease in risk with increasing physical activity. We used an approach similar to Parkin [23] to transform the RR estimates to $\mathrm{RR}$ for each of the categories of deficit in physical activity. The WCRF CUP does not present a RR per MET-h for endometrial cancer, so for endometrial cancer, we used the same RR as for breast cancer, which again is the approach used by Parkin [23]. A more detailed description of the calculation of RR estimates is found in Appendix B. To take into account that the introduction of a change in prevalence will take some time to reach its full effect, the Prevent model includes a LAT and LAG time. During the LAT time, the risk remains unchanged, and during the LAG time, the risk among previously exposed gradually changes to reach the risk among never exposed (or unexposed). We used a LAT time of 1 year and a LAG time of 9 years, with the RR changing linearly during the LAG time.

We investigated three hypothetical scenarios A, $\mathrm{B}$ and $\mathrm{C}$, to show the potential impact of changes in physical activity levels on the cancer burden relative to continued constant physical activity levels.

A Elimination of insufficient levels of physical activity in 2016

The prevalence of high, moderate and low deficit in MET-h was set to 0 . This is equivalent to everyone engaging in physical activity of at least 15 MET-h per week from the year 2016. This is comparable to PAF estimates.

B 50\% Reduction of proportion in each of the groups with insufficient levels of physical activity ( $<15$ MET-h per week) by 2025

Within this scenario, the prevalence in all groups of deficit (i.e. $<15$ MET-h per week) decreases with a constant annual percentage change for 10 years, so that the country-, age- and gender-specific prevalence within each group is reduced by $50 \%$ by 2025 .

C No one is in the group with high deficit $(<3$ MET-h per week) by 2025

Within this scenario, the prevalence in the group with high deficit in physical activity (i.e. $<3$ MET-h per week) is set to $0 \%$ by year 2025 , by first changing the country-, age- and gender-specific prevalence with a constant annual percentage change for 9 years reaching $0.1 \%$ in 2024 and then dropping to $0 \%$ in 2025 .

All scenarios were assumed to start in 2016 to allow for comparisons with our estimates for the Nordic countries made for other modifiable risk factors [11-13]. The number of avoidable postmenopausal breast, colon and endometrial cancers under each scenario was calculated for the 30-year period, 2016-2045. All scenarios were applied separately to each age- and gender-specific prevalence, and it is assumed that interventions move individuals to the group with sufficient level of physical activity (i.e. at least 15 MET-h per week), so the decrease in any of the groups with insufficient level of physical activity (low deficit [ 9 to $<15$ MET-h per week], medium deficit $[3 \mathrm{t}$ to $<9]$ and high deficit $[0$ to $<3]$ ) leads to an increase in the group with sufficient level of physical activity (15+ MET-h per week).

Sensitivity analyses were carried out to estimate the influence of varying LAT and LAG as well as the inclusion of a trend in cancer incidence and are described in Appendix C.

\section{Results}

The numbers and percentages of avoidable cancers in the Nordic countries for the whole 30 -year study period and for the year 2045 alone are presented in Table 2, by cancer site and scenario. Under constant levels of physical activity (base scenario), approximately 1.2 million cancer cases are expected for the three studied cancer sites in the Nordic countries over the period 2016-2045. In total, 11,000 cancers out of these could be avoided by eliminating deficit in physical activity (scenario A), which corresponds to $0.9 \%$ of the expected number of cases for these three sites (Table 2). The highest numbers and percentage of avoidable cancers are seen for colon cancer (6400 cases, 1.3\%). 
Table 2

Number (\#) and percentage of avoidable cancers during 2016-2045 and in 2045 in the Nordic countries, under different scenarios of physical activity levels, compared with constant levels. (The numbers in parentheses refer to the single year 2045.)

\begin{tabular}{|c|c|c|c|c|c|c|}
\hline \multirow[t]{2}{*}{ Cancer site } & \multicolumn{2}{|c|}{ Scenario $\mathrm{A}^{\mathrm{a}}$} & \multicolumn{2}{|c|}{ Scenario $\mathrm{B}^{\mathrm{b}}$} & \multicolumn{2}{|c|}{ Scenario $\mathrm{C}^{\mathrm{c}}$} \\
\hline & $\#$ & $\%$ & \# & $\%$ & \# & $\%$ \\
\hline Breast, age $50+$ & $\begin{array}{l}3546 \\
(153)\end{array}$ & $\begin{array}{l}0.6 \\
(0.7)\end{array}$ & $\begin{array}{l}1513 \\
(76)\end{array}$ & $\begin{array}{l}0.3 \\
(0.4)\end{array}$ & $\begin{array}{l}1467 \\
(68)\end{array}$ & $\begin{array}{l}0.3 \\
(0.3)\end{array}$ \\
\hline Colon & $\begin{array}{l}6413 \\
(294)\end{array}$ & $\begin{array}{l}1.3 \\
(1.6)\end{array}$ & $\begin{array}{l}2769 \\
(147)\end{array}$ & $\begin{array}{l}0.6 \\
(0.8)\end{array}$ & $\begin{array}{l}2812 \\
(136)\end{array}$ & $\begin{array}{l}0.6 \\
(0.7)\end{array}$ \\
\hline Endometrium & $\begin{array}{l}857 \\
(38)\end{array}$ & $\begin{array}{l}0.6 \\
(0.7)\end{array}$ & $\begin{array}{l}369 \\
(18)\end{array}$ & $\begin{array}{l}0.3 \\
(0.3)\end{array}$ & $\begin{array}{l}351 \\
(15)\end{array}$ & $\begin{array}{l}0.3 \\
(0.3)\end{array}$ \\
\hline Total $^{\mathrm{d}}$ & $\begin{array}{l}10,816 \\
(484)\end{array}$ & $\begin{array}{l}0.9 \\
(1.1)\end{array}$ & $\begin{array}{l}4651 \\
(241)\end{array}$ & $\begin{array}{l}0.4 \\
(0.5) \\
\end{array}$ & $\begin{array}{l}4630 \\
(219)\end{array}$ & $\begin{array}{l}0.4 \\
(0.5)\end{array}$ \\
\hline
\end{tabular}

MET, metabolic equivalents.

a A total elimination of deficit in physical activity in year 2016.

b $50 \%$ reduction of proportion in all groups with $<15$ MET-hours per week by 2025 .

${ }^{\mathrm{c}}$ No one with $<3$ MET-hours per week by 2025 .

${ }^{d}$ Percentage of avoidable cancer cases out of total number of expected cases for the three selected cancer sites.

Scenarios $\mathrm{B}$ and $\mathrm{C}$ give very similar results, indicating that approximately $0.5 \%$ of the expected number of cases for these three cancer types could be avoided. Small differences in the percentage of avoidable cancers were seen across countries (Tables 3-7). The results from the sensitivity analyses are presented in Appendix C. The number of avoidable cancers differs somewhat between the different sensitivity analyses, but the percentage of avoidable cancers is fairly robust.

\section{Discussion}

We estimated the number of avoidable cancers of the breast, colon and endometrium in the Nordic countries

Table 3

Number (\#) and percentage of avoidable cancers during 2016-2045 and in 2045 in Denmark, under different scenarios of physical activity levels, compared with constant levels. (The numbers in parentheses refer to the single year 2045.)

\begin{tabular}{|c|c|c|c|c|c|c|}
\hline \multirow[t]{2}{*}{ Cancer site } & \multicolumn{2}{|c|}{ Scenario $\mathrm{A}^{\mathrm{a}}$} & \multicolumn{2}{|c|}{ Scenario $\mathrm{B}^{\mathrm{b}}$} & \multicolumn{2}{|c|}{ Scenario $\mathrm{C}^{\mathrm{c}}$} \\
\hline & \# & $\%$ & $\#$ & $\%$ & $\#$ & $\%$ \\
\hline reast, age $50+$ & $\begin{array}{l}930 \\
(38)\end{array}$ & $\begin{array}{l}0.6 \\
(0.7)\end{array}$ & $\begin{array}{l}395 \\
(19)\end{array}$ & $\begin{array}{l}0.3 \\
(0.4)\end{array}$ & $\begin{array}{l}415 \\
(18)\end{array}$ & $\begin{array}{l}0.3 \\
(0.3)\end{array}$ \\
\hline Colon & $\begin{array}{l}1574 \\
(71)\end{array}$ & $\begin{array}{l}1.3 \\
(1.5)\end{array}$ & $\begin{array}{l}676 \\
(35)\end{array}$ & $\begin{array}{l}0.6 \\
(0.8)\end{array}$ & $\begin{array}{l}742 \\
(35)\end{array}$ & $\begin{array}{l}0.6 \\
(0.8)\end{array}$ \\
\hline Endometrium & $\begin{array}{l}179 \\
(8)\end{array}$ & $\begin{array}{l}0.6 \\
(0.8)\end{array}$ & $\begin{array}{l}76 \\
(4)\end{array}$ & $\begin{array}{l}0.3 \\
(0.4)\end{array}$ & $\begin{array}{l}82 \\
(4)\end{array}$ & $\begin{array}{l}0.3 \\
(0.4)\end{array}$ \\
\hline Total $^{\mathrm{d}}$ & $\begin{array}{l}2683 \\
(117)\end{array}$ & $\begin{array}{l}0.9 \\
(1.1)\end{array}$ & $\begin{array}{l}1147 \\
(58)\end{array}$ & $\begin{array}{l}0.4 \\
(0.5)\end{array}$ & $\begin{array}{l}1239 \\
(57)\end{array}$ & $\begin{array}{l}0.4 \\
(0.5)\end{array}$ \\
\hline
\end{tabular}

MET, metabolic equivalents

${ }^{a}$ A total elimination of deficit in physical activity in year 2016.

b $50 \%$ reduction of proportion in all groups with $<15$ MET-hours per week by 2025

c No one with $<3$ MET-hours per week by 2025 .

${ }^{d}$ Percentage of avoidable cancer cases out of total number of expected cases for the three selected cancer sites.
Table 4

Number (\#) and percentage of avoidable cancers during 2016-2045 and in 2045 in Finland, under different scenarios of physical activity levels, compared with constant levels. (The numbers in parentheses refer to the single year 2045.)

\begin{tabular}{|c|c|c|c|c|c|c|}
\hline \multirow[t]{2}{*}{ Cancer site } & \multicolumn{2}{|c|}{ Scenario $\mathrm{A}^{\mathrm{a}}$} & \multicolumn{2}{|c|}{ Scenario $\mathrm{B}^{\mathrm{b}}$} & \multicolumn{2}{|c|}{ Scenario $\mathrm{C}^{\mathrm{C}}$} \\
\hline & $\#$ & $\%$ & $\#$ & $\%$ & \# & $\%$ \\
\hline Breast, a & $\begin{array}{l}672 \\
(29)\end{array}$ & $\begin{array}{l}0.5 \\
(0.6)\end{array}$ & $\begin{array}{l}283 \\
(14)\end{array}$ & $\begin{array}{l}0.2 \\
(0.3)\end{array}$ & $\begin{array}{l}252 \\
(12)\end{array}$ & $\begin{array}{l}0.2 \\
(0.3)\end{array}$ \\
\hline Colon & $\begin{array}{l}903 \\
(40)\end{array}$ & $\begin{array}{l}1.2 \\
(1.4)\end{array}$ & $\begin{array}{l}388 \\
(20)\end{array}$ & $\begin{array}{l}0.5 \\
(0.7)\end{array}$ & $\begin{array}{l}376 \\
(17)\end{array}$ & $\begin{array}{l}0.5 \\
(0.6)\end{array}$ \\
\hline Endom & $\begin{array}{l}154 \\
\text { (6) }\end{array}$ & $\begin{array}{l}0.5 \\
(0.6)\end{array}$ & $\begin{array}{l}66 \\
\text { (3) }\end{array}$ & $\begin{array}{l}0.2 \\
(0.3)\end{array}$ & $\begin{array}{l}56 \\
(2)\end{array}$ & $\begin{array}{l}0.2 \\
(0.2)\end{array}$ \\
\hline Total $^{\mathrm{d}}$ & $\begin{array}{l}1729 \\
(75)\end{array}$ & $\begin{array}{l}0.7 \\
(0.9)\end{array}$ & $\begin{array}{l}737 \\
\text { (37) }\end{array}$ & $\begin{array}{l}0.3 \\
(0.4)\end{array}$ & $\begin{array}{l}684 \\
(31)\end{array}$ & $\begin{array}{l}0.3 \\
(0.4)\end{array}$ \\
\hline
\end{tabular}

MET, metabolic equivalents.

a A total elimination of deficit in physical activity in year 2016

b $50 \%$ reduction of proportion in all groups with $<15$ MET-hours per week by 2025 .

${ }^{\mathrm{c}}$ No one with $<3$ MET-hours per week by 2025 .

d Percentage of avoidable cancer cases out of total number of expected cases for the three selected cancer sites.

in a 30-year period under different scenarios of improvement in leisure time physical activity levels compared with current levels. About 11,000 of these cancer cases could be avoided if everyone in the Nordic countries had a sufficient level of physical activity, which corresponds to $0.9 \%$ of the expected number of cases for the three cancer types where physical activity has been shown to reduce the risk. Similar results were observed between the two other scenarios, either reducing all groups with insufficient physical activity levels by $50 \%$ (scenario B) or eliminating the group with lowest levels of physical activity (scenario C).

When comparing our results for the year 2045 alone, which is beyond the influence of LAT and LAG times,

Table 5

Number (\#) and percentage of avoidable cancers during 2016-2045 and in 2045 in Iceland, under different scenarios of physical activity levels, compared with constant levels. (The numbers in parentheses refer to the single year 2045.)

\begin{tabular}{|c|c|c|c|c|c|c|}
\hline \multirow[t]{2}{*}{ Cancer site } & \multicolumn{2}{|c|}{ Scenario $\mathrm{A}^{\mathrm{a}}$} & \multicolumn{2}{|c|}{ Scenario $\mathrm{B}^{\mathrm{b}}$} & \multicolumn{2}{|c|}{ Scenario $\mathrm{C}^{\mathrm{c}}$} \\
\hline & \# & $\%$ & $\#$ & $\%$ & \# & $\%$ \\
\hline Breast, age $50+$ & $\begin{array}{l}57 \\
(3)\end{array}$ & $\begin{array}{l}0.8 \\
(1.0)\end{array}$ & $\begin{array}{l}25 \\
(1)\end{array}$ & $\begin{array}{l}0.3 \\
(0.3)\end{array}$ & $\begin{array}{l}31 \\
(2)\end{array}$ & $\begin{array}{l}0.4 \\
(0.6)\end{array}$ \\
\hline Colon & $\begin{array}{l}78 \\
(4)\end{array}$ & $\begin{array}{l}1.6 \\
(2.0)\end{array}$ & $\begin{array}{l}34 \\
(2)\end{array}$ & $\begin{array}{l}0.7 \\
(1.0)\end{array}$ & $\begin{array}{l}46 \\
\text { (3) }\end{array}$ & $\begin{array}{l}1.0 \\
(1.5)\end{array}$ \\
\hline Endometrium & $\begin{array}{l}9 \\
(0)\end{array}$ & $\begin{array}{l}0.8 \\
(0)\end{array}$ & $\begin{array}{l}4 \\
(0)\end{array}$ & $\begin{array}{l}0.3 \\
(0)\end{array}$ & $\begin{array}{l}5 \\
(0)\end{array}$ & $\begin{array}{l}0.4 \\
(0)\end{array}$ \\
\hline Total $^{\mathrm{d}}$ & $\begin{array}{l}144 \\
\text { (7) }\end{array}$ & $\begin{array}{l}1.1 \\
(1.3)\end{array}$ & $\begin{array}{l}63 \\
\text { (3) }\end{array}$ & $\begin{array}{l}0.5 \\
(0.5)\end{array}$ & $\begin{array}{l}82 \\
(5)\end{array}$ & $\begin{array}{l}0.6 \\
(0.9)\end{array}$ \\
\hline
\end{tabular}

MET, metabolic equivalents.

${ }^{a}$ A total elimination of deficit in physical activity in year 2016.

b $50 \%$ reduction of proportion in all groups with $<15$ MET-hours per week by 2025 .

${ }^{c}$ No one with $<3$ MET-hours per week by 2025 .

${ }^{d}$ Percentage of avoidable cancer cases out of total number of expected cases for the three selected cancer sites. 
Table 6

Number (\#) and percentage of avoidable cancers during 2016-2045 and in 2045 in Norway, under different scenarios of physical activity levels, compared with constant levels. (The numbers in parentheses refer to the single year 2045.)

\begin{tabular}{|c|c|c|c|c|c|c|}
\hline \multirow[t]{2}{*}{ Cancer site } & \multicolumn{2}{|c|}{ Scenario $A^{a}$} & \multicolumn{2}{|c|}{ Scenario $\mathrm{B}^{\mathrm{b}}$} & \multicolumn{2}{|c|}{ Scenario $\mathrm{C}^{\mathrm{C}}$} \\
\hline & \# & $\%$ & \# & $\%$ & \# & $\%$ \\
\hline Breast, age $50+$ & $\begin{array}{l}624 \\
(28)\end{array}$ & $\begin{array}{l}0.7 \\
(0.8)\end{array}$ & $\begin{array}{l}269 \\
(14)\end{array}$ & $\begin{array}{l}0.3 \\
(0.4)\end{array}$ & $\begin{array}{l}245 \\
(12)\end{array}$ & $\begin{array}{l}0.3 \\
(0.3)\end{array}$ \\
\hline Colon & $\begin{array}{l}1666 \\
(80)\end{array}$ & $\begin{array}{l}1.4 \\
(1.6)\end{array}$ & $\begin{array}{l}726 \\
(40)\end{array}$ & $\begin{array}{l}0.6 \\
(0.8)\end{array}$ & $\begin{array}{l}670 \\
(34)\end{array}$ & $\begin{array}{l}0.6 \\
(0.7)\end{array}$ \\
\hline Endometrium & $\begin{array}{l}195 \\
\text { (9) }\end{array}$ & $\begin{array}{l}0.7 \\
(0.8)\end{array}$ & $\begin{array}{l}84 \\
(4)\end{array}$ & $\begin{array}{l}0.3 \\
(0.3)\end{array}$ & $\begin{array}{l}74 \\
\text { (3) }\end{array}$ & $\begin{array}{l}0.3 \\
(0.3)\end{array}$ \\
\hline Total $^{\mathrm{d}}$ & $\begin{array}{l}2485 \\
(117)\end{array}$ & $\begin{array}{l}1.0 \\
(1.2)\end{array}$ & $\begin{array}{l}1079 \\
(58)\end{array}$ & $\begin{array}{l}0.5 \\
(0.6)\end{array}$ & $\begin{array}{l}989 \\
(49)\end{array}$ & $\begin{array}{l}0.4 \\
(0.5)\end{array}$ \\
\hline
\end{tabular}

MET, metabolic equivalents.

${ }^{a}$ A total elimination of deficit in physical activity in year 2016 .

b $50 \%$ reduction of proportion in all groups with $<15$ MET-hours per week by 2025 .

${ }^{\mathrm{c}}$ No one with $<3$ MET-hours per week by 2025.

${ }^{\mathrm{d}}$ Percentage of avoidable cancer cases out of total number of expected cases for the three selected cancer sites.

Table 7

Number (\#) and percentage of avoidable cancers during 2016-2045 and in 2045 in Sweden, under different scenarios of physical activity levels, compared with constant levels. (The numbers in parentheses refer to the single year 2045.)

\begin{tabular}{|c|c|c|c|c|c|c|}
\hline \multirow[t]{2}{*}{ Cancer site } & \multicolumn{2}{|c|}{ Scenario $\mathrm{A}^{\mathrm{a}}$} & \multicolumn{2}{|c|}{ Scenario $\mathrm{B}^{\mathrm{b}}$} & \multicolumn{2}{|c|}{ Scenario $\mathrm{C}^{\mathrm{C}}$} \\
\hline & \# & $\%$ & \# & $\%$ & \# & $\%$ \\
\hline Breast, age $50+$ & $\begin{array}{l}1263 \\
(55)\end{array}$ & $\begin{array}{l}0.6 \\
(0.7)\end{array}$ & $\begin{array}{l}541 \\
(28)\end{array}$ & $\begin{array}{l}0.3 \\
(0.4)\end{array}$ & $\begin{array}{l}524 \\
(24)\end{array}$ & $\begin{array}{l}0.3 \\
(0.3)\end{array}$ \\
\hline Colon & $\begin{array}{l}2192 \\
(99)\end{array}$ & $\begin{array}{l}1.3 \\
(1.6)\end{array}$ & $\begin{array}{l}945 \\
(50)\end{array}$ & $\begin{array}{l}0.6 \\
(0.8)\end{array}$ & $\begin{array}{l}978 \\
(47)\end{array}$ & $\begin{array}{l}0.6 \\
(0.7)\end{array}$ \\
\hline Endometrium & $\begin{array}{l}320 \\
(14)\end{array}$ & $\begin{array}{l}0.6 \\
(0.7)\end{array}$ & $\begin{array}{l}139 \\
(7)\end{array}$ & $\begin{array}{l}0.3 \\
(0.4)\end{array}$ & $\begin{array}{l}134 \\
\text { (6) }\end{array}$ & $\begin{array}{l}0.3 \\
(0.3)\end{array}$ \\
\hline Total $^{\mathrm{d}}$ & $\begin{array}{l}3775 \\
(168)\end{array}$ & $\begin{array}{l}0.9^{\mathrm{d}} \\
(1.0)^{\mathrm{d}}\end{array}$ & $\begin{array}{l}1625 \\
(85)\end{array}$ & $\begin{array}{l}0.4^{\mathrm{d}} \\
(0.5)^{\mathrm{d}}\end{array}$ & $\begin{array}{l}1636 \\
(77)\end{array}$ & $\begin{array}{l}0.4^{d} \\
(0.5)^{d}\end{array}$ \\
\hline
\end{tabular}

MET, metabolic equivalents.

${ }^{a}$ A total elimination of deficit in physical activity in year 2016.

b $50 \%$ reduction of proportion in all groups with $<15$ MET-hours per week by 2025 .

${ }^{\mathrm{c}}$ No one with $<3$ MET-hours per week by 2025 .

${ }^{d}$ Percentage of avoidable cancer cases out of total number of expected cases for the three selected cancer sites.

with estimates of the PAF from other studies [23,25-29], our results are lower. This is probably because the Nordic populations tend to be more physically active compared with other Western populations [7]and also because of differences in the way the calculations were made. A comparison of the PAF estimates across studies is difficult because of great heterogeneity between studies. The methodology for measuring physical activity, differing definitions of sufficient levels of physical activity, varying effect sizes of the RR estimates, as well as measures of different domains of physical activity (i.e. occupational, leisure time and total), lead to differing PAF values. We based our calculations on the RR estimates for recreational physical activity in MET-h published by the WCRF CUP [1], with a lower reduction in risk compared with the RR estimates used by Parkin, Brown et al. and Brenner $[23,26,27]$ and lower than indicated by other studies $[25,30]$. De Vries et al. used the Prevent model to estimate the impact of increasing physical activity on colon cancer incidence in seven European countries. They found the proportion of avoidable cancer cases in Denmark to be $6 \%$ for males and $11 \%$ for females in a 30 -year period [31]. The reason for the large discrepancy between our study and the results from de Vries et al. is likely because of the use of different RR estimates but to some extent also because of a difference in how physical activity was measured and categorised. The RR estimates in the study by de Vries et al. were close to RR estimates seen in other studies when comparing lowest to highest groups in terms of physical activity, but they applied the RR estimates to all subjects with less than recommended levels of physical activity in comparison to those with physical activity levels according to recommendations.

For prevention of cancer, the optimal levels of physical activity according to domain, intensity and frequency are not well established. However, there is strong evidence for a dose-response relationship between increasing levels of physical activity and reduced risk of breast and colon cancer, as well as moderate evidence of a dose-response effect for endometrial cancer [32]. The WHO recommends at least $150 \mathrm{~min}$ of moderate or $75 \mathrm{~min}$ of vigorous physical activity weekly, which is equivalent to 7.5 MET$\mathrm{h}$. However, we estimated the number of avoidable cancer cases based on the assumption that sufficient physical activity requires 15 MET-h or more weekly. This cut-off point is in accordance with the cut-off point used by Parkin [23]. In addition, the cut-off point is in accordance with the WHO's statement that for additional health benefits, adults should increase their moderate or vigorous intensity physical activity to $300 \mathrm{~min}$ or $150 \mathrm{~min}$ per week, respectively. One should also keep in mind that the minimum WHO guidelines for physical activity are not specifically defined for reducing cancer risk but rather to be generic in relation to reducing the risk of several noncommunicable diseases.

Our study has some limitations. NORMO data for physical activity are self-reported, and it is well known that people tend to overestimate their level of physical activity [33]. In the collection of data, the participants were told to round the level of both moderate and vigorous activities to the nearest half hour, which could potentially lead to overestimation of the physical activity level. To counteract this potential bias, we used conservative estimates of MET-h. Second, we used RR estimates for breast cancer to estimate the number of preventable cancers of endometrial cancer, a similar approach as Parkin [23]. Third, we based our calculations on a single domain of physical activity (leisure time including transportation), and it might not reflect the 
total level of physical activity of the population. Additionally, we did not differentiate the type of recreational physical activity, i.e. running, gardening etc., because the data do not allow this distinction. This does not allow for a nuanced estimation for each of the Nordic countries, where e.g. cycling as transportation (4.0-6.8 MET-h) is dominant in Denmark, in contrast to cross country skiing (6.8-9.0 MET-h) which is more common in Norway, Finland and Sweden [34].

One limitation of the Prevent model is that it does not provide any uncertainty measure, such as confidence intervals. It is therefore important to do sensitivity analyses, which in our study indicates that the percentage of avoidable cancers is fairly robust to changes in LAT and LAG times, as well as to incorporating a trend in the cancer incidence. Even so, the results should be interpreted with caution, as the main purpose of the model is not to produce valid estimates of the future cancer burden but rather show the difference in the number of cases under different levels of exposure prevalence.

We did not take any other changes in modifiable risk behaviour into consideration, which could have an undefined impact on the results. Increased levels of physical activity could potentially result in reduced sedentary behaviour and healthier dietary habits. Evidence suggests that physical activity and sedentary behaviour may be inversely correlated [35], but we did not include data for sedentary behaviour. However, it would be relevant to perform similar calculations on preventable cancer cases and the potential of reducing sedentary behaviour such as TV-viewing and computer screen time in the Nordic countries, since sedentary behaviour is considered an independent risk factor of several types of cancer $[32,36]$.

Furthermore, we did not adjust for the interaction with overweight. An increase in physical activity could also lead to a lower prevalence of overweight and obesity, which would add to the number of avoidable cancer cases. Our previous study showed that an elimination of overweight and obesity in the Nordic countries would avoid 40,000 postmenopausal breast cancer cases in a 30-year period, 45,000 colon cancer cases and 33,000 endometrial cancer cases [11].

In addition, we have chosen to include the cancer sites for which there is strong evidence of a protective effect of physical activity. Studies have shown that more cancer sites than those included here could be associated with insufficient physical activity [5,6], and the number of avoidable cancers could therefore be larger. For instance, Moore et al. found an inverse association between physical activity and the risk of oesophageal adenocarcinoma, cancers of the liver, lung, kidney, bladder, head and neck, rectum, gastric cardia as well as myeloid leukaemia and myeloma, in addition to the three sites included in our study, namely colon, endometrial and postmenopausal breast cancer [5]. Still, the literature is conflicting, and many studies only compare groups with highest and lowest physical activity levels which is not enough for our calculations.

Our results show a potential of increasing physical activity for cancer prevention in the Nordic countries. From a public health perspective, it is also important to increase the level of physical activity since regular physical activity prevents several other noncommunicable diseases, e.g. cardiovascular diseases, type 2 diabetes mellitus and overweight and obesity [37-40]. Hence, interventions aiming to raise the level of physical activity in the Nordic countries should be prioritised. However, interventions as well as physical activity recommendations to the public should be held at a realistic level to encourage the population to adopt a more physically active lifestyle. Engaging in $5 \mathrm{~h}$ physical activity with moderate intensity per week corresponding to at least 15 MET-h might be considered realistic for the Nordic populations to achieve (scenario A), but it would probably take years of structural changes and interventions to achieve. In addition, our estimations revealed an effect of about 4600 preventable cases, if all groups with insufficient levels of physical activity were reduced by $50 \%$, or if the group with least physical activity was eliminated. These are more realistic scenarios. Either way, it requires political endorsement, infrastructural policy development and effective health policies as well as the engagement of health organisations, public health authorities and other relevant stakeholders working in close cooperation and over a long time to plan and implement effective structural changes and long-term interventions aiming to increase the levels of physical activity in the Nordic countries.

\section{Acknowledgements}

Funding: This study was funded by strategic funds from Danish Cancer Society and Nordic Cancer Union (NCU).

\section{Conflict of interest statement}

None declared.

\section{Appendix A. Supplementary data}

Supplementary data to this article can be found online at https://doi.org/10.1016/j.ejca.2019.01.008.

\section{References}

[1] World Cancer Research Fund/American Institute for Cancer Research. Diet, nutrirtion, physical activity and cancer: a global perspective. Continuous update Project expert report. 2018. Available at: dietandcancereport.org.

[2] Friedenreich C, Norat T, Steindorf K, Boutron-Ruault MC, Pischon T, Mazuir M, et al. Physical activity and risk of colon and rectal cancers: the European prospective investigation into cancer 
and nutrition. Cancer Epidemiol Biomark Prev 2006;15(12): $2398-407$.

[3] Friedenreich C, Cust A, Lahmann PH, Steindorf K, BoutronRuault MC, Clavel-Chapelon F, et al. Physical activity and risk of endometrial cancer: the European prospective investigation into cancer and nutrition. Int J Canc 2007;121(2):347-55.

[4] Steindorf K, Ritte R, Eomois PP, Lukanova A, Tjonneland A, Johnsen NF, et al. Physical activity and risk of breast cancer overall and by hormone receptor status: the European prospective investigation into cancer and nutrition. Int J Canc 2013;132(7):1667-78.

[5] Moore SC, Lee IM, Weiderpass E, Campbell PT, Sampson JN, Kitahara CM, et al. Association of leisure-time physical activity with risk of 26 types of cancer in 1.44 million adults. JAMA Intern Med 2016;176(6):816-25.

[6] Leitzmann M, Powers H, Anderson AS, Scoccianti C, Berrino F, Boutron-Ruault MC, et al. European code against cancer 4th edition: physical activity and cancer. Cancer Epidemiol 2015; 39(Suppl 1):S46-55.

[7] Guthold R, Stevens GA, Riley LM, Bull FC. Worldwide trends in insufficient physical activity from 2001 to 2016: a pooled analysis of 358 population-based surveys with 1.9 million participants. Lancet Glob Health 2018;6(10):e1077-86.

[8] Barendregt JJ. EpiGear. Brisbane. 2009. http://epigear.com/index. htm. [Accessed April 2016].

[9] Gunningschepers L. The health benefits of prevention - a simulation approach. Health Policy 1989;12(1-2):1-255.

[10] Soerjomataram I, de Vries E, Engholm G, Paludan-Muller G, Bronnum-Hansen H, Storm HH, et al. Impact of a smoking and alcohol intervention programme on lung and breast cancer incidence in Denmark: an example of dynamic modelling with Prevent. Eur J Cancer 2010;46(14):2617-24.

[11] Andersson TM, Weiderpass E, Engholm G, Lund AQ, Olafsdottir E, Pukkala E, et al. Avoidable cancer cases in the Nordic countries - the impact of overweight and obesity. Eur J Cancer 2017;79:106-18.

[12] Andersson TM, Engholm G, Pukkala E, Stenbeck M, Tryggvadottir L, Storm H, et al. Avoidable cancers in the Nordic countries-The impact of alcohol consumption. Eur J Cancer 2018 Nov; 103:299-307.

[13] Andersson TM, Engholm G, Brink AL, Pukkala E, Stenbeck M, Tryggvadottir L, et al. Tackling the tobacco epidemic in the Nordic countries and lower cancer incidence by $1 / 5$ in a 30 -year period-The effect of envisaged scenarios changing smoking prevalence. Eur J Cancer 2018 Nov;103:288-98.

[14] Engholm G, Ferlay J, Christensen N, Bray F, Gjerstorff ML, Klint A, et al. NORDCAN - a Nordic tool for cancer information, planning, quality control and research. Acta Oncologica 2010;49(5):725-36.

[15] Engholm GFJ, Christensen N, Kejs AMT, Johannesen TB, Khan S, Leinonen MK, et al. NORDCAN: cancer incidence, mortality, prevalence and survival in the nordic countries. Version 7.2. Association of the Nordic Cancer Registries. (Danish Cancer Society.); 16.12.2015. Available from: http://www.ancr.nu. accessed March 2016.

[16] Pukkala E, Engholm G, Hojsgaard Schmidt LK, Storm H, Khan S, Lambe M, et al. Nordic Cancer Registries - an overview of their procedures and data comparability. Acta Oncol 2018;57(4):440-55.

[17] https://www.ssb.no/en/befolkning/statistikker/folkfram/aar/201406-17. [Accessed February 2017].

[18] http://www.statistikdatabasen.scb.se/pxweb/en/ssd/START_BE_ BE0401_BE0401B/BefolkprognRev2015/table/tableViewLayout1/ ?rxid=a439aeld-ac32-4126-9a74-422e36b18ede. In; Accessed: February 2017.

[19] www.statbank.dk/FRLD115. . In; Accessed: February 2017.

[20] http://statice.is/statistics/population/population-projections/ population-projections/. In; Accessed: February 2017.

[21] http://pxnet2.stat.fi/PXWeb/pxweb/en/StatFin/StatFin_vrm_ vaenn/010_vaenn_tau_101.px/table/tableViewLayout1/?rxid=19a 48ea9-8c7f-4bf8-83fa-10f1 b6da8e94. In; Accessed: February 2017.
[22] World Health Organisation. Global recommendations on physical activity for health. 2010. Geneva.

[23] Parkin DM. 9. Cancers attributable to inadequate physical exercise in the UK in 2010. Br J Canc 2011;105(Suppl 2):S38-41.

[24] World Cancer Research Fund/American Institute for Cancer Research. In: Diet, nutrirtion, physical activityand cancer: a global perspective. Continuous update Project expert report 2018; 2018. Available at: dietandcancereport.org.

[25] Friedenreich CM, Neilson HK, Lynch BM. State of the epidemiological evidence on physical activity and cancer prevention. Eur J Cancer 2010;46(14):2593-604.

[26] Brown KF, Rumgay H, Dunlop C, Ryan M, Quartly F, Cox A, et al. The fraction of cancer attributable to modifiable risk factors in England, Wales, Scotland, Northern Ireland, and the United Kingdom in 2015. Br J Canc 2018;118(8):1130-41.

[27] Brenner DR. Cancer incidence due to excess body weight and leisure-time physical inactivity in Canada: implications for prevention. Prev Med 2014;66:131-9.

[28] Borch KB, Weiderpass E, Braaten T, Jareid M, Gavrilyuk OA, Licaj I. Physical activity and risk of endometrial cancer in the Norwegian Women and Cancer (NOWAC) study. Int J Canc 2017;140(8):1809-18.

[29] Islami F, Goding Sauer A, Miller KD, Siegel RL, Fedewa SA, Jacobs EJ, et al. Proportion and number of cancer cases and deaths attributable to potentially modifiable risk factors in the United States. Ca - Cancer J Clin 2018;68(1):31-54.

[30] Liu L, Shi Y, Li T, Qin Q, Yin J, Pang S, et al. Leisure time physical activity and cancer risk: evaluation of the WHO's recommendation based on 126 high-quality epidemiological studies. Br J Sports Med 2016;50(6):372-8.

[31] de Vries E, Soerjomataram I, Lemmens VE, Coebergh JW, Barendregt JJ, Oenema A, et al. Lifestyle changes and reduction of colon cancer incidence in Europe: a scenario study of physical activity promotion and weight reduction. Eur J Cancer 2010; 46(14):2605-16.

[32] 2018 Physical Activity Guidelines Advisory Committee. 2018 physical activity guidelines advisory committee scientific report. Washington, DC: U.S. Department of Health and Human Services; 2018.

[33] Lee PH, Macfarlane DJ, Lam TH, Stewart SM. Validity of the International Physical Activity Questionnaire Short Form (IPAQSF): a systematic review. Int J Behav Nutr Phys Activ 2011;8:115.

[34] Ainsworth BE, Haskell WL, Herrmann SD, Meckes N, Bassett D, Tudor-Locke C, et al. 2011 Compendium of Physical Activities: a second update of codes and MET values. Med Sci Sports Exerc 2011;43(8):1575-81.

[35] O’Donoghue G, Perchoux C, Mensah K, Lakerveld J, van der Ploeg H, Bernaards C, et al. A systematic review of correlates of sedentary behaviour in adults aged 18-65 years: a socio-ecological approach. BMC Public Health 2016;16:163.

[36] Kerr J, Anderson C, Lippman SM. Physical activity, sedentary behaviour, diet, and cancer: an update and emerging new evidence. Lancet Oncol 2017;18(8):e457-71.

[37] Johnsen NF, Ekblond A, Thomsen BL, Overvad K, Tjonneland A. Leisure time physical activity and mortality. Epidemiology 2013;24(5):717-25.

[38] Lachman S, Boekholdt SM, Luben RN, Sharp SJ, Brage S, Khaw KT, et al. Impact of physical activity on the risk of cardiovascular disease in middle-aged and older adults: EPIC Norfolk prospective population study. Eur J Prev Cardiol 2018;25(2):200-8.

[39] Kyu HH, Bachman VF, Alexander LT, Mumford JE, Afshin A, Estep K, et al. Physical activity and risk of breast cancer, colon cancer, diabetes, ischemic heart disease, and ischemic stroke events: systematic review and dose-response meta-analysis for the Global Burden of Disease Study 2013. BMJ 2016;354:i3857.

[40] Wiklund P. The role of physical activity and exercise in obesity and weight management: time for critical appraisal. J Sport Health Sci 2016;5(2):151-4. 